\title{
Retinopathy of prematurity screening leading to cardiopulmonary arrest: fatal complication of a benign procedure
}

\author{
Yashwant Agrawal, ${ }^{1}$ Sandeep Patri, ${ }^{2}$ Jagadeesh K Kalavakunta, ${ }^{3}$ Vishal Gupta ${ }^{3}$
}

${ }^{1}$ Western Michigan University Homer Stryker School of Medicine, Kalamazoo, Michigan, USA

${ }^{2}$ Western Michigan University

School of Medicine, Kalamazoo, Michigan, USA

${ }^{3}$ Borgess Medical Center/ Michigan State University, Kalamazoo, Michigan, USA

\section{Correspondence to} Dr Yashwant Agrawal, yashwantagrawal.agrawal@ gmail.com

Accepted 17 July 2016
CrossMark

\footnotetext{
To cite: Agrawal Y, Patri $S$, Kalavakunta JK, et al. BMJ Case Rep Published online: [please include Day Month Year] doi:10.1136/bcr-2016216594
}

\section{SUMMARY}

A 6-week-old female infant born at 31 weeks of gestation was brought to the ophthalmology office for retinopathy of prematurity (ROP) screening. One drop of phenylephrine $(2.5 \%)$ and tropicamide (1\%) ophthalmic solution was instilled in each eye for ROP evaluation. She was breast fed about $5 \mathrm{~min}$ after receiving the medication. She was covered in a blanket and soon her mother could not feel her suckling. Cardiopulmonary resuscitation was initiated with return of spontaneous circulation in 1-2 min. She was admitted to the paediatric intensive care unit and monitored overnight. After an uncomplicated hospital course, she was discharged the following day. It was determined that the eye drops had induced cardiopulmonary arrest (CPA) as apnoea and bradycardia of prematurity resolve by 36 weeks and CPA occurred within minutes of the medication administration. Identification of CPA, prompt intervention and awareness of the offending agent is of prime importance in management of such complications.

\section{BACKGROUND}

This case calls attention to the fact that systemic absorption of topical ophthalmic medications used for retinopathy of prematurity (ROP) screening can induce asystole, apnoea and altered mental status. Premature infants are predisposed to complications secondary to their immature cardiovascular and nervous systems. Phenylephrine has been known to cause hypertension and bradycardia when absorbed systemically, inducing reflex vasovagal response. Clinician awareness of such fatal complications is of prime importance given the fragile nature of patients involved. This case also highlights the need to accurately recognise and manage cardiopulmonary arrest (CPA) in an outpatient setting.

\section{CASE PRESENTATION}

A 6-week-old female infant presented to the ophthalmology outpatient clinic for evaluation of ROP. She was born a premie at 31 weeks of gestation with a birth weight of $1.32 \mathrm{~kg}$ and was hospitalised for 40 days in the neonatal intensive care unit (ICU) for respiratory distress syndrome and hyperbilirubinaemia. She did not have any other significant medical history. She had been on respiratory support for 9 days after birth. At the time of discharge, she was in good health status without any need for outpatient medications. During clinical follow-up at 6 weeks when her weight was $2.02 \mathrm{~kg}$, she received phenylephrine $2.5 \%$ and tropicamide
$1 \%$ ophthalmic solution, one drop of both medications in each eye for ROP evaluation. She was breast fed for about $5 \mathrm{~min}$ after receiving the medication. She was covered in a blanket and soon her mother could not feel her suckling. On examination, she was unresponsive, cyanotic, apnoeic and pulseless.

Cardiopulmonary resuscitation was initiated with return of spontaneous circulation in 1-2 min. She was admitted to the paediatric ICU where laboratory tests, chest radiograph, ECG and echocardiogram were unremarkable. She was placed on a continuous cardiac monitor and observed overnight. Following an uncomplicated hospital course she was discharged the next day. It was determined that the eye drops had induced CPA in our patient (corrected age of 37 weeks) as CPA occurred within minutes of the medication administration. Moreover, apnoea and bradycardia of prematurity resolve by 36 weeks.

\section{INVESTIGATIONS}

Complete blood picture, complete metabolic profile, serial troponins, chest X-ray, ECG and echocardiogram were normal.

\section{TREATMENT}

After initial cardiopulmonary resuscitation, the patient was placed on continuous cardiac monitoring. She did not require any medications to be administered.

\section{OUTCOME AND FOLLOW-UP}

She was discharged after overnight observation in the paediatric ICU. She had ROP screening in the cardiology office, 1-month later when her weight was $3.05 \mathrm{~kg}$ with the same medication as before with continuous cardiac monitoring. At this time she did not have any ROP. She has been doing well in outpatient follow-ups without any medical problems.

\section{DISCUSSION}

Phenylephrine $2.5 \%$, in conjunction with tropicamide is often used for ROP screening of premature infants to induce mydriasis. Phenylephrine is an $\alpha$-adrenergic medication which causes mydriasis without cycloplegia by direct action on the pupillary dilator muscle $\alpha$-adrenergic receptors. ${ }^{1}$ Tropicamide is an anticholinergic agent that causes cycloplegia and mydriasis by inhibiting pupillary constriction, ciliary muscle contraction and also by 
blocking the pupillary sphincter muscle. ${ }^{2}$ When used in conjunction these medications have a synergistic mydriatic effect. ${ }^{2} 3$

Topical ophthalmic medications bypass the first-pass metabolism by the gastrointestinal and hepatic systems by virtue of which they are directly absorbed into the systemic circulation. ${ }^{4}$ The immature cardiovascular and nervous systems compounded by the low body mass of premature infants makes them highly susceptible to the toxicity of these medications. ${ }^{5}$

Phenylephrine when absorbed systemically can induce a transitory hypertensive and bradycardic response which can lead to CPA. ${ }^{6}$ Cardiopulmonary adverse effects of tropicamide include

\section{Learning points}

- Phenylephrine has been known to cause hypertension and bradycardia when absorbed systemically, inducing a reflex vasovagal response.

- Premature infants are at an increased risk of these complications secondary to their immature cardiovascular and nervous systems.

- Practitioners who handle newborns should consider cardiovascular monitoring with availability of emergent resuscitation equipment when administering such medications, especially in premature infants to prevent fatal complications. apnoea, tachycardia and oxygen desaturation which in the presence of phenylephrine can be synergistic leading to CPA. ${ }^{16}$

Apnoea and bradycardia of prematurity is a known pathology in babies with $<1 \mathrm{~kg}$ birth weight, but it resolves by a corrected gestational age of 36 weeks. $^{6}$ The cause of CPA in our patient was in all likelihood from the topical ophthalmic medication, given her corrected gestational age was 37 weeks. Moreover, CPA occurred immediately after the medication was administered.

Contributors YA took care of the patient in the paediatric intensive care unit. SP saw the patient in the outpatient ophthalmology office. JKK and VG who were in the neighbouring offices resuscitated the patient.

Competing interests None declared.

Patient consent Obtained.

Provenance and peer review Not commissioned; externally peer reviewed.

\section{REFERENCES}

1 Mitchell AJ, Green A, Jeffs DA, et al. Physiologic effects of retinopathy of prematurity screening examinations. Adv Neonatal Care 2011;11:291-7.

2 Fleck BW, Dhillon B, Mitchell A. Additive mydriatic effect of $2.5 \%$ phenylephrine and $0.5 \%$ tropicamide eyedrops in premature babies. J Pediatr Ophthalmol Strabismus 1994;31:130.

3 Bolt B, Benz B, Koerner $F$, et al. A mydriatic eye-drop combination without systemic effects for premature infants: a prospective double-blind study. J Pediatr Ophthalmol Strabismus 1992;29:157-62.

4 Shiuey Y, Eisenberg MJ. Cardiovascular effects of commonly used ophthalmic medications. Clin Cardiol 1996;19:5-8.

5 Wheatcroft $S$, Sharma A, McAllister J. Reduction in mydriatic drop size in premature infants. Br J Ophthalmol 1993;77:364-5.

6 Wood MG, Kaufman LM. Apnea and bradycardia in two premature infants during routine outpatient retinopathy of prematurity screening. J AAPOS 2009;13:501-3.

Copyright 2016 BMJ Publishing Group. All rights reserved. For permission to reuse any of this content visit

http://group.bmj.com/group/rights-licensing/permissions.

BMJ Case Report Fellows may re-use this article for personal use and teaching without any further permission.

Become a Fellow of BMJ Case Reports today and you can:

- Submit as many cases as you like

- Enjoy fast sympathetic peer review and rapid publication of accepted articles

- Access all the published articles

- Re-use any of the published material for personal use and teaching without further permission

For information on Institutional Fellowships contact consortiasales@bmjgroup.com

Visit casereports.bmj.com for more articles like this and to become a Fellow 